\title{
High temperatures during microsporogenesis fatally shorten pollen lifespan
}

\author{
Maurizio lovane $^{1}$ (D) Giovanna Aronne ${ }^{1}$
}

Received: 5 February 2021 / Accepted: 28 June 2021 / Published online: 7 July 2021

(c) The Author(s) 2021

\begin{abstract}
Many crop species are cultivated to produce seeds and/or fruits and therefore need reproductive success to occur. Previous studies proved that high temperature on mature pollen at anther dehiscence reduce viability and germinability therefore decreasing crop productivity. We hypothesized that high temperature might affect pollen functionality even if the heat treatment is exerted only during the microsporogenesis. Experimental data on Solanum lycopersicum 'Micro-Tom' confirmed our hypothesis. Microsporogenesis successfully occurred at both high $\left(30^{\circ} \mathrm{C}\right)$ and optimal $\left(22^{\circ} \mathrm{C}\right)$ temperature. After the anthesis, viability and germinability of the pollen developed at optimal temperature gradually decreased and the reduction was slightly higher when pollen was incubated at $30^{\circ} \mathrm{C}$. Conversely, temperature effect was eagerly enhanced in pollen developed at high temperature. In this case, a drastic reduction of viability and a drop-off to zero of germinability occurred not only when pollen was incubated at $30^{\circ} \mathrm{C}$ but also at $22^{\circ} \mathrm{C}$. Further ontogenetic analyses disclosed that high temperature significantly speeded-up the microsporogenesis and the early microgametogenesis (from vacuolated stage to bi-cellular pollen); therefore, gametophytes result already senescent at flower anthesis. Our work contributes to unravel the effects of heat stress on pollen revealing that high temperature conditions during microsporogenesis prime a fatal shortening of the male gametophyte lifespan.
\end{abstract}

Keywords Microgametophyte $\cdot$ Pollen viability $\cdot$ Pollen germination $\cdot$ Heat waves $\cdot$ Pollen development $\cdot$ Tomato

\section{Introduction}

Successful interaction of pollen with the environment is essential in agricultural systems because most crop species are cultivated to produce seeds and/or fruits and therefore need fertilization to occur. Considering that in higher plants each pollen grain is a haploid gametophyte of only two (max three) cells generated by the diploid sporophyte through a meiosis (microsporogenesis), pollen ephemeral life is limited at producing two gametes (microgametogenesis), possibly after being transferred to a plant different from the one that generated it (cross-pollination). Despite the smallness of its size and the shortness of its life pollen grains of any species are autonomous organisms, genetically different

Communicated by Hugh G. Dickinson.

Maurizio Iovane

maurizio.iovane@unina.it

1 Department of Agricultural Sciences, University of Naples Federico II, Naples, Italy from any other and subject to the interaction with the environment. Pollen grains are exposed to natural selection and can influence the genetic constitution of the resulting sporophytic generation (Mulcahy 1979). The possibility to screen the individuals best adapted to specific environmental conditions is the concept which gametophytic selection is based on and proposed as alternative to the much wider used sporophytic selection for crop species (Hormaza and Herrero 1996). Although the studies on the effects of external factors on pollen biology are mainly focused on mature and/ or germinated grains, environmental conditions affect pollen at all development stages, including the microsporogenesis (Pacini and Dolferus 2019).

Interaction of pollen with environmental factors is relevant not only for crop production on Earth but also for long term mission in Space. Indeed, pollen functionality has a key role in implementing bioregenerative life support systems (BLSSs) for long duration space-flight missions. Therefore, research on interaction between pollen and environmental factors, in addition to space factors as simulated 
microgravity (De Micco et al. 2006), is essential to realize the seed-to-seed cycle also on board spacecraft.

Considering recent projections of climate changes, a rising concern for gradual increases and abrupt variations of temperature is leading research to select genotypes tolerant to high temperatures or heat waves and to clarify the physiological processes involved in heat-stress responses (Hedhly et al. 2009; Mesihovic et al. 2016). Generally in plants, pollen functionality is strongly affected by high temperatures, alone or in interaction with RH (Aronne 1999). More particularly, high temperatures are well known to affect pollen viability, pollen germinability and fertilization both in crops and in other plant species (Pérez et al. 2019; Aronne et al. 2015).

Pollen sterility induced by high temperature stress is an agricultural problem because it limits the productivity of many crop species (Pacini and Dolferus 2019). Negative effects of high temperature on pollen functionality constitute possible bottlenecks in plant life cycle of many species and conditions (De Micco et al. 2014; Aronne 2017). Therefore, a deep understanding on how high temperatures affect pollen functionality is essential to ensure food security.

At present, a special need to deepen pollen reaction to altered temperature conditions is relevant not only to predict the effect of gradual global warming on crop productions, but also to prevent the effect of sudden changes of temperatures during single producing cycles. Such events of heat waves are not rare in open field and in greenhouses and might strongly affect quantity and quality of crop production (Ledesma and Kawabata 2016).

Previous studies on the effect of high temperature at flowering, generally focus their attention on the functionality of the male gametophytes (Aronne et al. 2006, 2021; Djanaguiraman et al. 2019) and are performed incubating mature pollen grains samples after their release from the anthers (Dafni 1992). However, negative effects of high temperature before pollen development have been described on microsporogenesis of several species (Porch and Jahn 2001; Szalay et al. 2019; Masoomi-Aladizgeh et al. 2020). Among crops, a considerable amount of studies has been conducted to assess heat stress on tomato pollen, because of its agronomic relevance and its exposure to temperature fluctuations during flowering, both in open field and in greenhouse (Firon et al. 2006; Paupière et al. 2017a). In tomato heat stress is also reported to interfere with tapetum formation, exine deposition and vacuolization of mature microspores (Giorno et al. 2013) and also with starch accumulation (Pressman et al. 2002). These heat stress-induced defects are produced during the microsporogenesis, may strongly affect the progression of male gametogenesis, and therefore the correct formation and functionality of mature pollen. Notwithstanding the general knowledge on the effect of temperature on plant reproduction, specific studies aimed to investigate on possible relations between a heat stress occurred during the microsporogenesis and a later effect on the gametogenesis have been generally neglected.

Tomato is frequently used as model species for studies on interaction between high temperature and reproductive biology (Paupière et al. 2017b; Pham et al. 2020). In this work, we grew dwarf tomato plants under finely controlled temperature conditions to deepen the timing of pollen ontogenesis and to test the hypothesis that high temperature occurring during microsporogenesis can affect pollen formation and especially subsequent functionality of the male gametophyte.

\section{Material and methods}

The experiment was performed in two equal growth chambers (VELP ${ }^{\circledR}$, FOC 200IL). We used plants of Solanum lycopersicum 'Micro-Tom', a dwarf tomato selected to perform experiments in space. It is considered as an ideal model plant for experiments in confined environment because of its small habitus and its short life cycle (Matsukura et al. 2008). Among tomato cultivars, Micro-tom is used to elucidate the molecular mechanisms of reproductive biology traits in tomato because in addition to the small size and the short life cycle, it can be easily crossed with other tomato cultivars and genetically transformed (Sun et al., 2006). Moreover, the whole genome of Micro-Tom has been sequenced and made available in the 'TOMATOMICS' database (Kobayashi et al., 2014).

Plants were grown in plastic pots on a $1: 1(\mathrm{v} / \mathrm{v})$ soil and perlite medium. A photosynthetic photon flux (PPF) of 200 $\mu \mathrm{mol} \mathrm{m} \mathrm{m}^{-2} \mathrm{~s}^{-1}$ with a $16 \mathrm{~h} \mathrm{~d}^{-1}$ photoperiod was provided by white LEDs and relative humidity was kept at $70 \% \pm$ $5 \%$ throughout the whole experiment. At first, we grew 18 plants of Micro-Tom in a single growth chamber with an air temperature of $22{ }^{\circ} \mathrm{C} \pm 0.5^{\circ} \mathrm{C}$ (control temperature) generally considered as optimal for tomato (Sato et al. 2001; Matsuda et al. 2014). As soon as the primordia of the first inflorescences became visually distinguishable, we moved half plants in the other growth chamber in which all parameters were the same but the air temperature of $30^{\circ} \mathrm{C} \pm 0.5^{\circ} \mathrm{C}$ (high temperature). This approach was adopted to avoid possible effects of the two temperatures on vegetative phase of the plant growth and to ensure that the plants were exposed at the two different temperatures only during microsporogenesis. The high temperature treatment was designed and set in the growth chamber according to the screening for pollen tolerance in tomato reported by Paupière et al. (2017a) in which maximum average day temperatures for heat-tolerant tomato genotypes originated from location with hot environmental conditions varies from $28^{\circ} \mathrm{C}$ to $31^{\circ} \mathrm{C}$. 
We evaluated pollen functionality on a total amount of 72 flowers for each temperature treatment. For every single flower, the pollen from each anther was used for a single temperature treatment as specified below. To track pollen abortion, pollen viability and germinability during microsporogenesis and gametogenesis, therefore throughout flower lifespan, we collected flowers at four different flowering stages: (a) Closed calix, (b) Closed corolla, (c) Anthesis, (d) Post-anthesis (Fig. 1).

Pollen abortion at the end of microsporogenesis was measured using lactophenol-cotton blue stain that detects the presence of cytoplasm in pollen grains (RodriguezRiano and Dafni 2000). Pollen abortion was tested on 18 flowers for each temperature treatment occurring during microsporogenesis. Therefore, the pollen samples were collected from 36 anthers of different flowers buds with closed corolla. At this stage, we were able to compare the effect of the two temperature treatments occurring during microsporogenesis on pollen abortion, after microsporogenesis had ended. Each pollen sample was obtained by gently opening the undehisced anther with tweezers and spreading the pollen from a single anther directly on a 1 $\mu \mathrm{L}$ droplet of water previously placed on a slide. One droplet of $1 \mu \mathrm{L}$ of Lactophenol-cotton blue stain was added on each pollen sample and slides were mounted with a cover slip. We scored as non-aborted the pollen grains stained dark/blue and as aborted the ones that remained faint/colourless. Abortion percentage was measured counting at least 200 pollen grains per slide for a total of 36 slides (18 flowers $\times 2$ temperature treatments). Scoring was made using an Olympus ${ }^{\circledR}$ BX-60 light microscope.
To compare the effect of the two temperatures during microsporogenesis on gametophyte functionality, we evaluated pollen viability and germinability after 72 hours of incubation at $22{ }^{\circ} \mathrm{C}$ and $30{ }^{\circ} \mathrm{C}$. Half of the flowers developed under $22{ }^{\circ} \mathrm{C}$ were incubated at $22{ }^{\circ} \mathrm{C}$ and the other at $30^{\circ} \mathrm{C}$. Similarly, half of the flowers developed under $30^{\circ} \mathrm{C}$ were incubated at $22{ }^{\circ} \mathrm{C}$ and the other at $30{ }^{\circ} \mathrm{C}$. Overall, for each temperature treatment we incubated 27 flowers at $22{ }^{\circ} \mathrm{C}$ and 27 flowers at $30{ }^{\circ} \mathrm{C}$. More specifically, incubated flowers were distinct into three categories corresponding to the stages of (1) closed corolla, (2) anthesis, (3) post anthesis. Each flower of the same phenological stage was excised from a single inflorescence, placed in open Petri dishes and incubated in two different growth chambers set at $22{ }^{\circ} \mathrm{C}$ and $30{ }^{\circ} \mathrm{C}$ with $70 \% \mathrm{RH}$.

To minimize possible inter-flower variations, 4 anthers per flower/bud were each used to assess: (1) pollen viability after $72 \mathrm{~h}$ incubation at $22^{\circ} \mathrm{C}$, (2) pollen viability after 72 $\mathrm{h}$ incubation at $30^{\circ} \mathrm{C}, * 3$ ) pollen germinability after $72 \mathrm{~h}$ incubation at $22^{\circ} \mathrm{C}$, (4) pollen germinability after $72 \mathrm{~h}$ incubation at $30^{\circ} \mathrm{C}$.

Both for pollen viability and in vitro germination, three pollen samples of at least 200 grains were analysed per anther and scored with an Olympus ${ }^{\circledR}$ BX-60 light microscope.

To test pollen viability, we used diaminobenzidine (DAB) reaction because of its ease of use and its reliability to distinguish between viable and unviable pollen (Rodriguez-riano and Dafni 2000). For each sample, pollen from a single anther was spread on a slide. $1 \mu \mathrm{L}$ droplet of DAB solution was added on each pollen sample and slides were gently

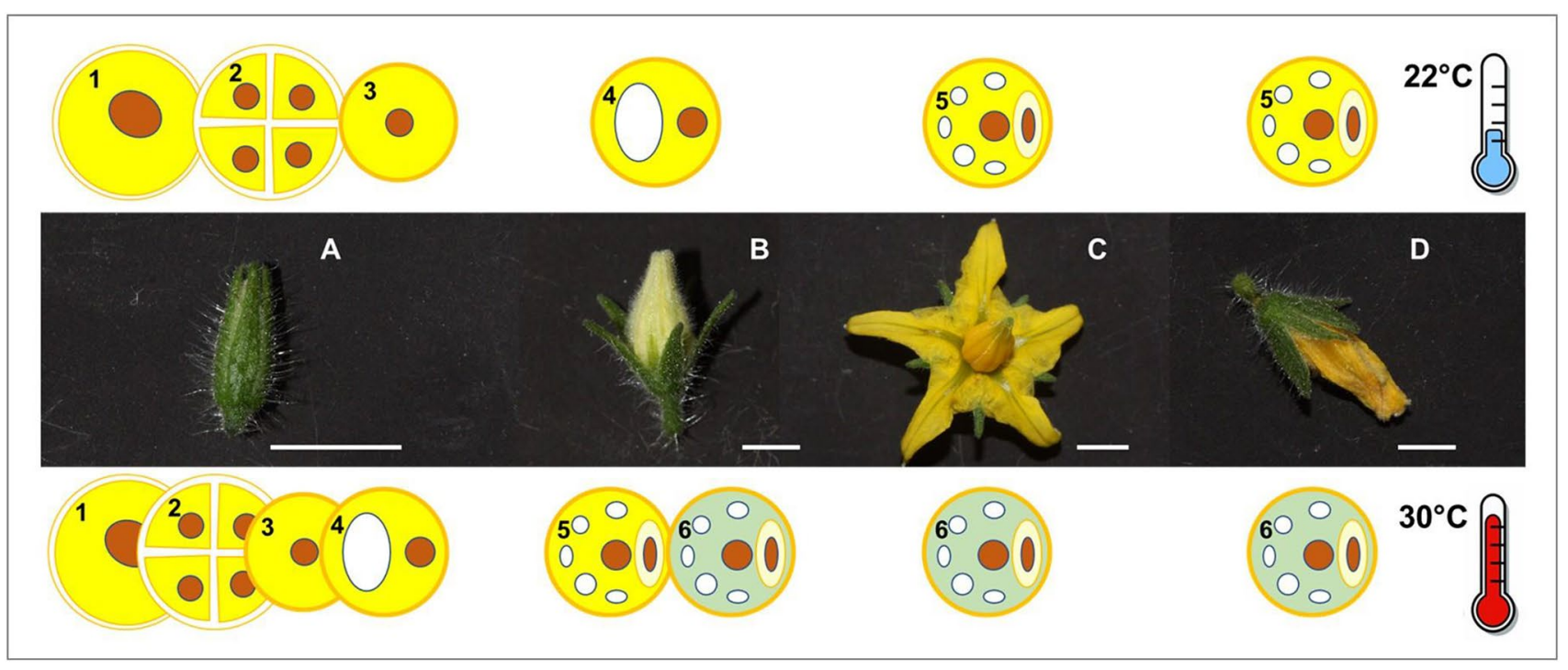

Fig. 1 Flowering stages and relative pollen development phases in flowers of tomato plants grown at $22{ }^{\circ} \mathrm{C}$ and $30^{\circ} \mathrm{C}$. Flowering stages: a Closed calix, b Closed corolla, c Anthesis, d Post-anthesis. Pollen developmental phases: (1) Pollen mother-cell, (2) Tetrad, (3) Unicellular microspore, (4) Vacuolated stage, (5) Bi-cellular pollen grain, (6) Dead pollen grain. Bars $=2 \mathrm{~mm}$ 
warmed on a heating plate. When pollen was dry, slides were mounted with a cover slip and immediately microscope analysed. We scored as viable only pollen grains that turned totally black or dark brown.

In vitro pollen germination was tested through the hanging drop method using a germination medium modified from Karapanos et al. (2010) and Song et al. (1999) and optimized for Micro-Tom pollen. One droplet of germination medium was deposited on a cover slip and pollen from a single anther was released inside the droplet before turning the cover slip upside down. To prevent dehydration, slides with the hanging drops were stored in petri dishes sealed with parafilm. To evaluate in vitro pollen germination, hanging drops were incubated at either $22{ }^{\circ} \mathrm{C}$ or $30^{\circ} \mathrm{C}$ for $24 \mathrm{~h}$. Grains were scored as germinated when the pollen tube was longer than the pollen diameter.

To analyse pollen ontogenesis, we collected flower buds at different developmental stages, extracted the anthers with the help of an Olympus ${ }^{\circledR}$ SZX10 stereomicroscope and squashed them on microscope slides. We used different staining techniques on different anthers of single flowers. More specifically, to distinguish between well developed and aborted pollen we used aceto-carmine, toluidine blue and aniline blue staining procedures (Dafni 1992). Stained samples were observed with an Olympus ${ }^{\circledR}$ BX-60 light and epi-fluorescent microscope and results were cross-linked to get a comprehensive overview of the processes.

Data were analysed with IBM ${ }^{\circledR}$ SPSS Statistics. The Shapiro Wilk's test and Levene's test were, respectively, used to assess the normality and homogeneity of the variances of the datasets. Differences between the two temperatures during microsporogenesis on pollen abortion were compared with a t-test $(p<0.05)$. As concern pollen viability

A Flowers developed at $22^{\circ} \mathrm{C}$

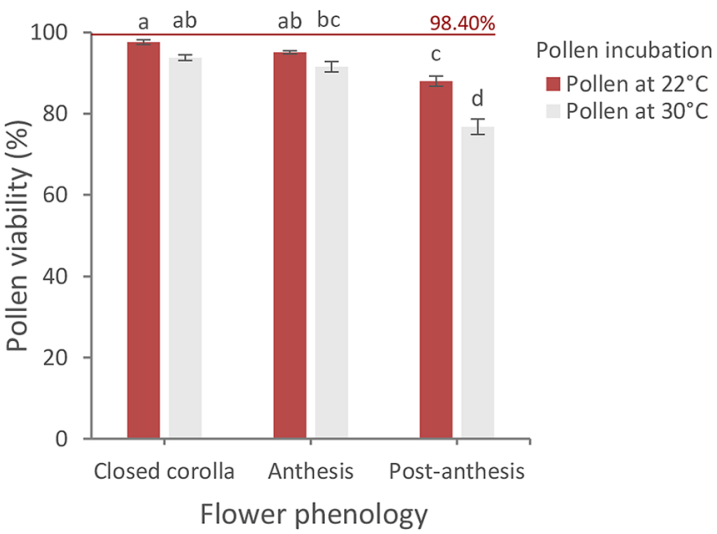

Fig. 2 Viability of pollen from flower at different phenological stages and incubated for $72 \mathrm{~h}$ at $22{ }^{\circ} \mathrm{C}$ and $30{ }^{\circ} \mathrm{C}$. Data from flowers in which microsporogenesis occurred at $22{ }^{\circ} \mathrm{C}$ (a) and $30{ }^{\circ} \mathrm{C}$ (b). Hori- and germination, results were obtained from a three-factorial design ( 2 temperatures during microsporogenesis, 2 of incubation, 3 flower/bud types, 9 replicates) and significant differences were tested with a three-way ANOVA $(p<0.05)$. The Tukey HSD test $(p<0.05)$ was used for post-hoc analysis. Results expressed as percentage were converted with arcsine function.

\section{Results}

The Micro-tom plants grown at $22^{\circ} \mathrm{C}$ during the vegetative phase and subsequently grown at $22{ }^{\circ} \mathrm{C}$ and $30{ }^{\circ} \mathrm{C}$ during the reproductive phase, compared to those always kept at $22^{\circ}$, did not show visual differences in terms of growth rate, flowering time and flower morphology (colour and size).

Microscopic analysis showed that the microsporogenesis occurred in buds at the stage of closed calix and is completed at the stage of closed corolla both in flowers developed at $22{ }^{\circ} \mathrm{C}$ and in those developed at $30^{\circ} \mathrm{C}$.

The lactophenol-cotton blue test performed on pollen coming from flower buds with closed corolla revealed that the number of not aborted/well-formed pollen grains was high in flowers developed under both temperature treatments. However, at closed corolla stage, percentage of not aborted pollen resulted only slightly lower $(p<0.05)$ at $30{ }^{\circ} \mathrm{C}(97.64 \%)$ compared to $22{ }^{\circ} \mathrm{C}(99.22 \%)$. Nevertheless, higher temperature during microsporogenesis did not lowered so much the number of well-formed pollen grains. Overall, the lactophenol-cotton blue test proved that higher temperature during microsporogenesis did not interfere so much with the first stages of pollen development and that the great majority of the grains in the anthers at the stage

\section{B Flowers developed a $30^{\circ} \mathrm{C}$}

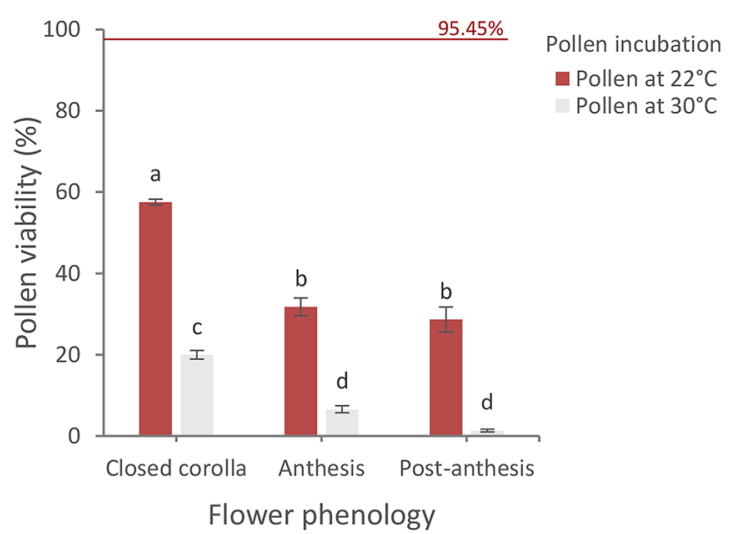

zontal lines show well-developed pollen percentage at anthesis before incubation. Significant differences between phenological stages are expressed with different letters $(p<0.05)$. Bars represent \pm SE 
of closed corolla was well formed and functional in both temperature treatments.

Prolonging the temperature treatments on flowers up to the stage of anthesis and testing pollen viability with the DAB enzymatic reaction, we verified that most of the grains at anther dehiscence resulted viable in flowers from both temperature treatments. Percentage of viable grains in flowers developed at $22{ }^{\circ} \mathrm{C}$ was statistically not different to that of flowers at $30{ }^{\circ} \mathrm{C}(98.40 \%$ and $95.45 \%$ respectively, $p<$ 0.01) (Fig. 2). Therefore, high temperature during flower development and microsporogenesis did not lowered pollen viability at the beginning of the anthesis.

The scenario changed completely when we collected the pollen from plants treated at the two temperatures during flowering/microsporogenesis development and subsequently incubated the grains at the same and cross changed two temperatures. Results of the DAB viability tests were analysed according to a three-factorial design including 2 temperatures during microsporogenesis, 2 incubation temperatures and 3 flower/bud types. The three-ways ANOVA revealed that the temperature during microsporogenesis resulted the main factor affecting pollen viability $(\mathrm{F}=6455.24, p<$ 0.05 ) along all the flowering stages: closed corolla, anthesis, post-anthesis (Fig. 2). When microsporogenesis occurred at optimal temperature $\left(22{ }^{\circ} \mathrm{C}\right)$, pollen viability gradually decreased remaining quite high along the whole flowering, ranging from $97.60 \%$ (closed corolla) to $76.77 \%$ (postanthesis) (Fig. 2a). Conversely, higher temperature $\left(30{ }^{\circ} \mathrm{C}\right)$ during microsporogenesis (flower development) drastically reduced pollen viability from $57.49 \%$ (closed corolla) to $1.32 \%$ (post-anthesis) (Fig. 2b). According to the ANOVA, the main effect of the incubation temperature was also significant $(p<0.01)$ but it was strongly influenced by the interaction with the microsporogenesis temperature. Particularly,

\section{A Flowers developed at $22^{\circ} \mathrm{C}$}

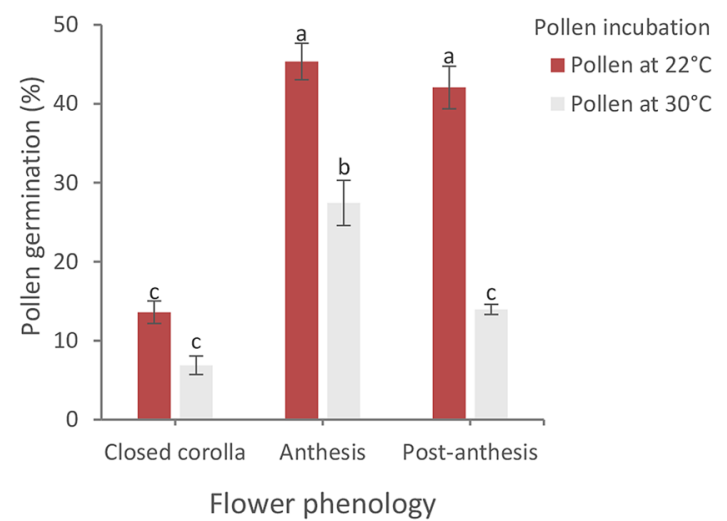

Fig. 3 Germinability of pollen from flower at different phenological stages and incubated for $72 \mathrm{~h}$ at $22{ }^{\circ} \mathrm{C}$ and $30{ }^{\circ} \mathrm{C}$. Data from flowers in which microsporogenesis occurred at $22{ }^{\circ} \mathrm{C}$ (a) and $30^{\circ} \mathrm{C}$ (b). Sig- data showed that pollen in which microsporogenesis had occurred at optimal temperature, resulted more thermotolerant to the following exposure to incubation temperature; indeed, almost all pollen grains that lactophenol-cotton blue test detected as not aborted at closed corolla stage (99.22\%) remained viable till anthesis stage without significant difference between $30^{\circ}$ incubation $(91.54 \%)$ at $22{ }^{\circ} \mathrm{C}(95.10 \%)$ (Fig. 2a).

Higher temperature during microsporogenesis strongly reduced pollen thermotolerance to higher incubation temperature: indeed, pollen viability after $30^{\circ} \mathrm{C}$ incubation resulted significantly lower than $22^{\circ} \mathrm{C}$ in each phenological stage and most importantly, almost all grain did not survived $30{ }^{\circ} \mathrm{C}$ incubation at anthesis stage (6.56\%) (Fig. 2b).

Overall, results showed that higher temperature occurring during microsporogenesis amplified the effect of the incubation temperature on pollen viability.

Effects on gametophyte functionality (pollen tube development) of high temperature treatment exerted during the microsporogenesis resulted significant. Data on pollen grains developed under the two temperatures and subsequently incubated to germinate at the same and at cross changed temperatures showed clear significant differences. More specifically, the three-way ANOVA revealed as significant $(p<0.01)$ the main effect of each factor and their interaction on germination percentage. According to the results, when microsporogenesis occurred at $30^{\circ} \mathrm{C}$, almost no grain developed a pollen tube independently from incubation temperature and flowering stage (Fig. 3b). When microsporogenesis occurred at optimal temperature, highest percentages of germinability occurred using pollen from flowers at the anthesis and percentages significantly decreased in pollen from flowers in post-anthesis (Fig. 3). Post-hoc analysis on the interaction between flower phenological stages and

\section{B Flowers developed at $30^{\circ} \mathrm{C}$}

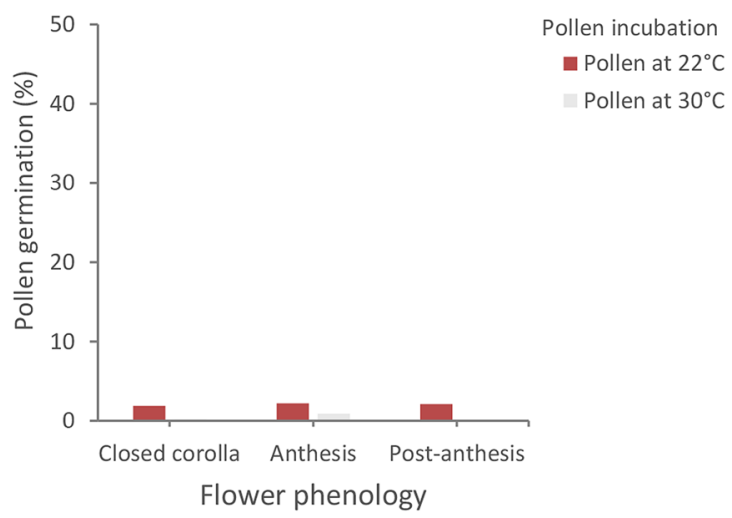

nificant differences between phenological stages are expressed with different letters $(p<0.05)$. Bars represent \pm SE 
incubation temperature showed that at $22^{\circ} \mathrm{C}$ the decrease in pollen germinability was not significant passing from anthesis to post-anthesis. Incubation at $30^{\circ} \mathrm{C}$ temperature not only significantly decreased pollen germinability in comparison to lower temperature but halved the percentage from anthesis (27.44\%) to post-anthesis stage (13.96\%) (Fig. 3a).

Data on germinability of pollen from flowers at closed corolla stage deserve special considerations. Percent germination of pollen from closed-corolla flowers resulted much lower than that from flowers at the anthesis and germinability apparently increased passing from the closed corolla to the anthesis stage. Such a phenomenon is not linked to the loss of viability (that instead resulted very high using the LCB and DAB tests). In-depth microscopy observations showed that when flowers are developed at $22{ }^{\circ} \mathrm{C}$, pollen in buds at the stage of closed corolla represent gametophytes not yet mature to develop the pollen tube (Fig. 1).

Overall, results of germination tests revealed that both microsporogenesis temperature and the following exposure to incubation temperature are essential to ensure pollen tube development at anthesis stage when pollination should naturally occur.

Further microscope observations aimed to deepen the effects of high temperature on pollen ontogenesis and to identify possible cytological differences during pollen development, revealed large differences on pollen development associated to temperature exposure of the anthers during microsporogenesis. Analysis of anther sections stained with aniline blue showed that high temperature conditions during microsporogenesis altered the timing of the developmental stages of pollen throughout flowering (Fig. 1). At the stage of closed calix, pollen mother cells, tetrads and uni-cellular microspores were observed in both treatments. Moreover, at the same stage, some microspores passed to the "vacuolated phase" only in anthers exposed to high temperature. At optimal temperature, pollen development resulted slower, and vacuolated microspores were observed from closed corolla stage on. Besides, temperature exposure of microspores affected the timing of the bi-cellular stage.

After the microsporogenesis, almost all microspores exposed to high temperature prematurely underwent the first haploid mitosis turning into mature pollen grains (bi-cellular gametophytes) at the stage of closed corolla. In flowers developed at $22{ }^{\circ} \mathrm{C}$, the bi-cellular stage became visible only from the anthesis stage, when mature pollen is expected to be ready for dispersal. From anthesis stage on, aniline blue stain highlighted differences in viability between the temperature treatments. In flowers developed at $22{ }^{\circ} \mathrm{C}$ mature pollen was well-developed with densely stained cytoplasm from anthesis to post-anthesis stage. Differently, in anthers developed under high temperature, pollen cytoplasm drastically degenerated from closed corolla stage on and almost all pollen resulted aborted at post-anthesis.
Overall, cytological analysis allowed to clarify that the high temperature speeded up microspore transition into the male gametophyte (bi-cellular stage) and reduced pollen lifespan throughout flowering. In flowers developed at optimal temperature the presence of mature pollen in the anthers occurred as expected at the anthesis stage, while in flowers developed under high temperature pollen was ready for dispersal and fertilization when the flower was still a bud. At high temperature most of grains had lost their viability from anther dehiscence on and grains resulted too old to germinate at the anthesis stage.

\section{Discussion}

The experimental setup and design of using reversible combination of optimal and high temperature conditions during microsporogenesis and microgametogenesis allowed to disclose that a heat stress occurring only during microspore formation may become manifest later on the male gametophyte. Data showed that the drastic reduction of the male gametophyte functionality occurred even if the number of well-developed pollen grains at anther dehiscence resulted comparable to that of pollen developed at optimal temperature. Further microscopic analyses on pollen ontogenesis explained the relations between high temperature during microsporogenesis and high reduction of the male gametophyte functionality. The investigation revealed that heat conditions accelerate the senescence processes up to the point that pollen although well-developed, is mostly dead already at anthesis, so even before pollination dispersal. These results are critical for the achievement of the reproductive success in terms of seed/fruit production, especially considering that frequency of extreme weather events is expected to increase in a climate change scenario (Hedhly 2011). In such scenarios, summer crops such as tomato, will be more often exposed to heat waves even during the earliest stages of flowering when pollen is still developing. To date, other studies have tested sensitivity of pollen to thermal insults which frequently occurs for summer crops growing both in open field and in greenhouses (e.g. Porch and Jahn 2001; Mesihovic et al. 2016; Paupière et al. 2017a).

Reproductive success and the achievement of the seed-toseed cycle is fundamental not only for crop cultivation also to reach the ambitious objective of realising complete selfsustaining cultivation systems for Space habitats (De Micco et al. 2014). Studies on plant biology in space reported that microgravity significantly affects pollen functionality interfering on several processes, including callose deposition at the end of the microsporogenesis (Kuang et al. 1995) or callose plugs formation in the male gametophyte (De Micco et al. 2006). Nevertheless, in addition to microgravity, interactions with other environmental factors have been identified 
as major contributors to male sterility in experiments conducted in space (Levinskikh et al. 2000; Campbell et al. 2001; Veselova, 2003). Sudden changes of temperatures can occur on board of space stations during the period needed to close the seed-to-seed cycle. Considering that tomato is one of the crop species selected for cultivations in space, our study furnishes new insights to define the scientific requirements for future experiments on tomato reproduction in space and to correctly interpret the results.

Focusing on the way tomato plants respond to the environmental temperature during reproduction, previous research reports high variability in pollen response within 22-30 ${ }^{\circ} \mathrm{C}$ temperature depending on how/when the temperature treatment was performed. For instance, Paupière et al. (2017a) reported significant loss of pollen viability on tomato when plants were exposed to high temperatures during the whole flowering. Conversely, Pham et al. (2020) did not found difference in terms of viability when pollen previously developed at optimal temperature was incubated at high temperature. Our results suggest that this variability in pollen thermo-tolerance is strictly linked to the pollen developmental stage targeted by heat treatment. Other studies on the effect of heat stress on tomato pollen report specific cytological anomalies including interferences during starch accumulation (Pressman et al. 2002) or exine formation and microspore vacuolization (Giorno et al. 2013); these processes occur during pollen ontogenesis and therefore might be involved in the lifespan and in the senescence speed of the pollen.

In the present work, pollen from flowers heat-treated during microsporogenesis always resulted significantly lower in viability compared to optimal temperature treatment while pollen in which microsporogenesis occurred at optimal temperature well tolerated both $22{ }^{\circ} \mathrm{C}$ and $30{ }^{\circ} \mathrm{C}$ incubation. Therefore, data showed that microsporogenesis occurring in the earliest stage of flower bud development represent a highly sensitive phase to high temperature exposure along the pollen ontogenesis. Although heat stress has already been reported to cause several dysfunctions in important monocot and dicot crops during early micropore stage, (Porch and Jahn 2001; Giorno et al. 2013; Jagadish et al. 2014; Szalay et al. 2019; Masoomi-Aladizgeh et al. 2020) none of these studies have described implications of these heat-stress induced defects on subsequent mature pollen viability and germinability, both essential to ensure fertilization success and crop productivity. According to our results, it seems that uni-cellular microspores are less adapted to deal with environmental factors until their transition into bi- or tri-cellular pollen grains.

Different strategies in response to heat stress have been described in pollen to preserve viability from anthesis to stigma landing including dehydration, accumulation of osmolytes and synthesis of protective molecules such as heat stress proteins enforcing membrane stability (Pacini and Dolferus 2019). Differences between uni-cellular microspores and two or three-cellular male gametophytes in tolerating high temperatures, could be related to their different capability to express their haploid genes to overcome environmental constraints. Therefore, results of the present study should be taken into account to perform successfully gametophytic selection in breeding protocols for new cultivars best adaptable to heat stress both for future space missions and for cultivations on earth.

Our data showed that the effects of high temperatures were even more severe on pollen germinability than on viability. Such a phenomenon has been reported for species other than tomato (Aronne et al. 2015; Jiang et al. 2015; Djanaguiraman et al. 2018). However, in our case a few Celsius degrees over optimal temperature occurring in the earliest stage of flowering resulted fatal for the gametophytes therefore causing a reproductive failure. Considering that pollen grains detected as viable through DAB reaction do not necessarily develop pollen tubes (Dafni 1992), it is therefore reasonable that pollen from the high temperature treatment showing a very low viability did not germinate. Germinability of pollen developed at optimal temperature increased along flowering and reached the maximum percentage at anthesis. These results are in line with our cytological analysis in which we assessed that the highest germination percentage corresponds to the bi-cellular stage that in the optimal temperature treatment occurred at anthesis. Indeed, tomato pollen is generally dispersed as bi-cellular gametophytes and the second mitotic division only occurs after germination on the stigma. In the high temperature treatment, all the developmental stages resulted speeded up compared to optimal temperature treatment. In particular, the transition into the bi-cellular stage representing the condition of mature pollen had already occurred before anthesis. We thus highlight that high temperatures during microsporogenesis also causes a premature transition of microspores into bicellular pollen to ensure mature pollen formation ready for dispersal but reducing pollen lifespan throughout flowering. Therefore, both direct effects of high temperature on the earliest stages of flower bud development and reduction of pollen lifespan throughout flowering can be responsible for a drastic loss in pollen viability and germinability.

Finally, the dwarf variety of tomato used for our experiment proved to be effective and further usable as a model for more studies on pollen functionality allowing to grow plants in small chambers where environmental parameters can be finely modulated and different temperature treatments can be performed during specific pollen developmental stages.

In conclusion, we successfully used tomato 'Micro-Tom' as model plant to contribute to the studies on the effects of heat stress on reproduction and verified the hypothesis that high temperature occurring during microsporogenesis 
can affect the subsequent functionality of the male gametophyte. Results also allowed to disclose that short periods of high temperature (as during the occurrence of heat waves) can accelerate pollen senescence processes priming a fatal shortening of the gametophyte lifespan and consequently a drop-off to zero of the viability before pollen is transferred by pollination.

Author contribution statement MI and GA equally contributed to conceptualization, investigation and writing.

Funding Open access funding provided by Università degli Studi di Napoli Federico II within the CRUI-CARE Agreement. Research was partially funded by Italian Space Agency, project ReBUS (In-situ Resource Bio-Utilization for life Support system) - Contract ASI N. 2019-4-U.0.

Data availability (Data transparency) Raw data can be provided upon request.

Code availability (software application or custom code) Not applicable.

\section{Declaration}

Conflicts of interest The authors have no conflicts of interest to declare that are relevant to the content of this article.

Open Access This article is licensed under a Creative Commons Attribution 4.0 International License, which permits use, sharing, adaptation, distribution and reproduction in any medium or format, as long as you give appropriate credit to the original author(s) and the source, provide a link to the Creative Commons licence, and indicate if changes were made. The images or other third party material in this article are included in the article's Creative Commons licence, unless indicated otherwise in a credit line to the material. If material is not included in the article's Creative Commons licence and your intended use is not permitted by statutory regulation or exceeds the permitted use, you will need to obtain permission directly from the copyright holder. To view a copy of this licence, visit http://creativecommons.org/licenses/by/4.0/.

\section{References}

Aronne G (1999) Effects of relative humidity and temperature stress on pollen viability of cistus incanus and myrtus communis. Grana 38(6):364-367. https://doi.org/10.1080/00173130050136154

Aronne G (2017) Identification of bottlenecks in the plant life cycle for sustainable conservation of rare and endangered species. Front Ecol Evol 5(JUL):1-7. https://doi.org/10.3389/fevo.2017.00076

Aronne G, De Micco V, Scala M (2006) Effects of relative humidity and temperature conditions on pollen fluorochromatic reaction of Rosmarinus officinalis L. (Lamiaceae). Protoplasma 228(13):127. https://doi.org/10.1007/s00709-006-0173-3

Aronne G, Buonanno M, De Micco V (2015) Reproducing under a warming climate: Long winter flowering and extended flower longevity in the only Mediterranean and maritime Primula. Plant Biol 17(2):535-544. https://doi.org/10.1111/plb.12239
Aronne G, Iovane M, Strumia S (2021) Temperature and humidity affect pollen viability and trigger distyly disruption in threatened species. Annali Di Botanica. https://doi.org/10.13133/2239-3129/ 17157

Campbell WF, Salisbury FB, Bugbee B, Klassen S, Naegle E, Strickland DT, Bingham GE, Levinkikn M, Iljina GM, Sytchev VN, Podolsky I, McManus WR, Bubenheim DL, Stieber J, Jahns G (2001) Comparative floral development of Mir-grown and ethylene-treated, Earth-grown Super Dwarf wheat. J Plant Physiol 158:1051-1060. https://doi.org/10.1078/S0176-1617(04)70129-7

Dafni A (1992) Pollination ecology: a practical approach. Oxford University Press, Oxford, UK

De Micco V, Scala M, Aronne G (2006) Effects of simulated microgravity on male gametophyte of Prunus, Pyrus, and Brassica species. Protoplasma 228(1-3):121-126. https://doi.org/10.1007/ s00709-006-0161-7

De Micco V, De Pascale S, Paradiso R, Aronne G (2014) Microgravity effects on different stages of higher plant life cycle and completion of the seed-to-seed cycle. Plant Biol 16:31-38. https://doi.org/10. 1111/plb.12098

Djanaguiraman M, Perumal R, Jagadish SVK, Ciampitti IA, Welti R, Prasad PVV (2018) Sensitivity of sorghum pollen and pistil to high-temperature stress. Plant, Cell Environ 41(5):1065-1082. https://doi.org/10.1111/pce.13089

Djanaguiraman M, Schapaugh W, Fritschi F, Nguyen H, Prasad PV (2019) Reproductive success of soybean (Glycine max L. Merril) cultivars and exotic lines under high daytime temperature. Plant, Cell Environ 42(1):321-336. https://doi.org/10.1111/pce.13421

Firon N, Shaked R, Peet MM, Pharr DM, Zamski E, Rosenfeld K, Althan L, Pressman E (2006) Pollen grains of heat tolerant tomato cultivars retain higher carbohydrate concentration under heat stress conditions. Sci Hortic 109(3):212-217. https://doi.org/10. 1016/j.scienta.2006.03.007

Giorno F, Wolters-Arts M, Mariani C, Rieu I (2013) Ensuring reproduction at high temperatures: the heat stress response during anther and pollen development. Plants 2(3):489-506. https://doi. org/10.3390/plants2030489

Hedhly A (2011) Sensitivity of flowering plant gametophytes to temperature fluctuations. Environ Exp Bot 74(1):9-16. https://doi.org/ 10.1016/j.envexpbot.2011.03.016

Hedhly A, Hormaza JI, Herrero M (2009) Global warming and sexual plant reproduction. Trends Plant Sci 14(1):30-36. https://doi.org/ 10.1016/j.tplants.2008.11.001

Hormaza JI, Herrero M (1996) Male gametophytic selection as a plant breeding tool. Sci Hortic 65(4):321-333. https://doi.org/10.1016/ 0304-4238(96)00899-0

Jagadish KS, Craufurd P, Shi W, Oane R (2014) A phenotypic marker for quantifying heat stress impact during microsporogenesis in rice (Oryza sativa L.). Funct Plant Biol 41(1):48-55. https://doi. org/10.1071/FP13086

Jiang Y, Lahlali R, Karunakaran C, Kumar S, Davis AR, Bueckert RA (2015) Seed set, pollen morphology and pollen surface composition response to heat stress in field pea. Plant, Cell Environ 38(11):2387-2397. https://doi.org/10.1111/pce.12589

Karapanos IC, Akoumianakis KA, Olympios CM, Passam HC (2010) Tomato pollen respiration in relation to in vitro germination and pollen tube growth under favourable and stress-inducing temperatures. Sex Plant Reprod 23(3):219-224. https://doi.org/10.1007/ s00497-009-0132-1

Kobayashi M, Nagasaki H, Garcia V, Just D, Bres C, Mauxion JP et al (2014) Genome-wide analysis of intraspecific DNA polymorphism in 'Micro-Tom', a model cultivar of tomato (Solanum lycopersicum). Plant Cell Physiol 55(2):445-454. https://doi.org/ $10.1093 / \mathrm{pcp} / \mathrm{pct} 181$

Kuang A, Musgrave ME, Matthews SW, Cummins DB, Tucker SC (1995) Pollen and ovule development in Arabidopsis thaliana 
under spaceflight conditions. American J Botany 82(5):585-595. https://doi.org/10.1002/j.1537-2197.1995.tb11503.x

Ledesma NA, Kawabata S (2016) Responses of two strawberry cultivars to severe high temperature stress at different flower development stages. Sci Hortic 211:319-327. https://doi.org/10.1016/j. scienta.2016.09.007

Levinskikh MA, Sychev VN, Derendyaeva TA, Signalova OB, Salisbury FB, Campbell WF, Bingham GE, Bubenheim DL, Jahns G (2000) Analysis of the spaceflight effects on growth and development of Super Dwarf wheat grown on the Space Station Mir. J Plant Physiol 156:522-529. https://doi.org/10.1016/S01761617(00)80168-6

Masoomi-Aladizgeh F, Najeeb U, Hamzelou S, Pascovici D, Amirkhani A, Tan DK, Atwell BJ (2020) Pollen development in cotton (Gossypium hirsutum) is highly sensitive to heat exposure during the tetrad stage. Plant, Cell Environ 42(1):321-336. https://doi.org/ $10.1111 /$ pce. 13421

Matsuda R, Ozawa N, Fujiwara K (2014) Leaf photosynthesis, plant growth, and carbohydrate accumulation of tomato under different photoperiods and diurnal temperature differences. Sci Hortic 170:150-158. https://doi.org/10.1016/j.scienta.2014.03.014

Matsukura C, Aoki K, Fukuda N, Mizoguchi T, Asamizu E, Saito T, Shibata D, Ezura H (2008) Comprehensive resources for tomato functional genomics based on the miniature model tomato MicroTom. Curr Genomics 9(7):436-443. https://doi.org/10.2174/ 138920208786241225

Mesihovic A, Iannacone R, Firon N, Fragkostefanakis S (2016) Heat stress regimes for the investigation of pollen thermotolerance in crop plants. Plant Reproduction 29(1-2):93-105. https://doi.org/ 10.1007/s00497-016-0281-y

Mulcahy DL (1979) The rise of the angiosperms: A genecological factor. Science 206(4414):20-23. https://doi.org/10.1126/scien ce. 206.4414 .20

Pacini E, Dolferus R (2019) Pollen developmental arrest: Maintaining pollen fertility in a world with a changing climate. Front Plant Sci 10(May):1-15. https://doi.org/10.3389/fpls.2019.00679

Paupière MJ, van Haperen P, Rieu I, Visser RGF, Tikunov YM, Bovy AG (2017) Screening for pollen tolerance to high temperatures in tomato. Euphytica. https://doi.org/10.1007/s10681-017-1927-z

Paupière MJ, Müller F, Li H, Rieu I, Tikunov YM, Visser RGF, Bovy AG (2017b) Untargeted metabolomic analysis of tomato pollen development and heat stress response. Plant Reproduction 30(2):81-94. https://doi.org/10.1007/s00497-017-0301-6

Pérez V, Herrero M, Hormaza JI (2019) Pollen performance in mango (Mangifera indica L., Anacardiaceae): Andromonoecy and effect of temperature. Scientia Horticulturae 253(April):439-446. https://doi.org/10.1016/j.scienta.2019.04.070
Pham D, Hoshikawa K, Fujita S, Fukumoto S, Hirai T, Shinozaki Y, Ezura H (2020) A tomato heat-tolerant mutant shows improved pollen fertility and fruit-setting under long-term ambient high temperature. Environ Exp Bot 178(June):104150. https://doi.org/ 10.1016/j.envexpbot.2020.104150

Porch TG, Jahn M (2001) Effects of high-temperature stress on microsporogenesis in heat-sensitive and heat-tolerant genotypes of Phaseolus vulgaris. Plant, Cell Environ 24(7):723-731. https://doi. org/10.1046/j.1365-3040.2001.00716.x

Pressman E, Peet MM, Pharr DM (2002) The effect of heat stress on tomato pollen characteristics is associated with changes in carbohydrate concentration in the developing anthers. Ann Bot 90(5):631-636. https://doi.org/10.1093/aob/mcf240

Rodriguez-Riano T, Dafni A (2000) A new procedure to asses pollen viability. Sex Plant Reprod 12(4):241-244. https://doi.org/10. 1007/s004970050008

Sato S, Peet MM, Gardner RG (2001) Formation of parthenocarpic fruit, undeveloped flowers and aborted flowers in tomato under moderately elevated temperatures. Sci Hortic 90(3-4):243-254. https://doi.org/10.1016/S0304-4238(00)00262-4

Song J, Nada K, Tachibana S (1999) Ameliorative effect of polyamines on the high temperature inhibition of in vitro pollen germination in tomato (Lycopersicon esculentum Mill.). Scientia Horticulturae 80(3-4):203-212. https://doi.org/10.1016/S0304-4238(98) 00254-4

Sun HJ, Uchii S, Watanabe S, Ezura H (2006) A highly efficient transformation protocol for Micro-Tom, a model cultivar for tomato functional genomics. Plant Cell Physiology 47(3):426-431. https://doi.org/10.1093/pcp/pci251

Szalay L, Froemel-Hajnal V, Bakos J, Ladányi M (2019) Changes of the microsporogenesis process and blooming time of three apricot genotypes (Prunus armeniaca L.) in Central Hungary based on long-term observation (1994-2018). Sci Hortic 246:279-288. https://doi.org/10.1016/j.scienta.2018.09.069

Veselova TD, Il'ina GM, Levinskikh MA, Sychev VN (2003) Ethylene is responsible for disturbed development of plant reproductive system under conditions of space flight. Russ J Plant Physiol 50:339-354. https://doi.org/10.1023/A:1023870120010

Publisher's Note Springer Nature remains neutral with regard to jurisdictional claims in published maps and institutional affiliations. 